\title{
Effect of Diversification on Portfolio Risk Management at Rwanda Social Security Board
}

\section{Jean Bosco Harelimana*}

Institut d'Enseignement Superieur de Ruhengeri, Musanze, Rwanda

*Corresponding author: Jean Bosco Harelimana, Institut d'Enseignement Superieur de Ruhengeri, Musanze, Rwanda, Tel:+250(0)788903032; E-mail: harelijordan@yahoo.fr

Received date: October 26, 2017; Accepted date: November 13, 2017; Published date: November 20, 2017

Copyright: ( 2017 Harelimana JB. This is an open-access article distributed under the terms of the Creative Commons Attribution License, which permits unrestricted use, distribution, and reproduction in any medium, provided the original author and source are credited.

\begin{abstract}
The study was conducted to analyze the effect of diversification on portfolio risk management at Rwanda Social Security Board (RSSB). Both primary and secondary data were collected under this study in order to capture the total variation of the two variables. A sample of 84 respondents out of 124 was selected using Solvins formula to respond the structured questionnaire and structured interviews. After coding and editing the data was analyzed using SPSS where the overall mean and deviation was used to observe the perception from respondents. The researcher found there was a significance strong relationship between diversification of portfolio on portfolio risk management at RSSB where the Pearson correlation coefficient was found to be 0.964 . However, recommendations given focusing on improvement of international diversification to reduce its portfolio risk, to reduce risks through the purchase of a mutual fund and should not directly invest in securities with maturities greater than the limits imposed by investment policy.
\end{abstract}

Keywords Portfolio; Risk management; Diversification

\section{Introduction}

According to Harvey, portfolio management is a highly deficient area globally and locally. By owning several assets, certain types of risk (in particular specific risk) can be reduced. The assets in the portfolio could include stocks, bonds, options, warrants, gold certificates, real estate, futures contracts, production facilities, or any other item that is expected to retain its value [1].

Ideally, every company should have a long term and short term financial plan guiding their financial decision. Holding a portfolio is part of an investment and risk-limiting strategy called diversification. Portfolio management involves deciding what assets to include in the portfolio, given the goals of the portfolio owner and changing economic conditions. Selection involves deciding what assets to purchase, how many to purchase, when to purchase them, and what assets to divest by observation. Some businesses, for instance, invest significant capital spending on programs and portfolios that do not directly align with strategic corporate objectives [1].

Others struggle to balance risk with the opportunities required to achieve these objectives. Many institutions are unable to accurately assess their portfolio's performance; RSSB is one of the institutions that use a diversification as key strategy to reduce portfolio risk. It is in this regards the researcher choose RSSB to show the role of diversification on portfolio risk management so that the study have great important to the other companies still struggling to manage their portfolio risk.

\section{Objectives}

The main objective of this study is to analyze the effect of diversification on portfolio risk management.
1. To determine the perception of the respondents on portfolio diversification at RSSB.

2. To determine the perception of the respondents on portfolio risk management at RSSB.

3. To measure the relationship between portfolio diversification and portfolio risk management at RSSB.

\section{Literature Review}

The basic definitions of the keywords are defined in this section where the literature was reviewed to strengthen the data under this study.

Risk is defined in different ways: It defines risk as measurable uncertainty. The other approach created correlates risks to the financial aspects; here, risk is defined as the volatility of expected results on the value of assets and liabilities of interest. However, the most relevant and popular well-known risk definition was made, stating that risk is "the exposure to a proposition of which one is uncertain".

Portfolio risk can be described as the variance of portfolio that refers to the possibility of loss or the percentage in which investor tolerates to compensate for their higher return. In the purpose of diversification, the risk of portfolio is significantly taken into consideration. Additionally, it is the only factor used currently to explain the superior benefit of portfolio compared to individual stock [2].

Investment portfolio is a set of financial or physical assets, which belongs to an investor. The main aim of setting or building portfolio is reducing risk through covering the risk of an instrument or an asset by returns of another. And also can be defined as "mix of weights of financial securities, or a set of ratios of securities which is owned by an investor". 
Portfolio theory was advanced by Harry Markowitz in 1952. He defines portfolio is a collection of securities. As most securities are available, investments have uncertain returns and thus risky, one needs to establish which portfolio to own. Markowitz asserts investors should base their portfolio decisions solely on expected returns and standard deviations. Investors should estimate the expected return and standard deviation of each portfolio and then choose the best one on the basis of these two parameters. Expected return can be viewed as a measure of potential reward associated with any portfolio over the holding period and standard deviation can be viewed as a measure of the risk associated with the portfolio [3].

Since an infinite number of portfolios can be constructed from a set of securities, the problem is to determine the most desirable portfolio. The Efficient Set Theorem states that an investor will choose his or her optimal portfolio from the set of portfolios that; (i) Offer maximum expected return for varying degrees of risk; and (ii) Offer minimum risk for varying levels of expected return. The set of portfolios meeting these two conditions is known as the efficient set (also known as efficient frontier).

The process will first involve identification of the feasible set which represents all portfolios that can be formed from a given number of securities. The investor will then select an optimal portfolio by plotting his or her indifference curve on the same figure as the efficient set and then proceed to choose the portfolio that is on the indifference curve that is farthest northwest. This portfolio will correspond to the point at which an indifference curve is just tangent to the efficient set. An investors' optimal portfolio is located at the tangency point between the investors' indifference curves and the efficient set [4].

Diversification is defined as a technique that reduces risk by allocating investments among a multitude of asset types. When you diversify, you try to ensure that at any given time, the value of some of your holdings might be down, and some might be up, but overall you are doing fine. Diversification strives to smooth out unsystematic risk events in a portfolio so that the positive performance of some investments will neutralize the negative performance of others. Therefore, the benefits of diversification will hold only if the securities in the portfolio are not perfectly correlated.

Conducted a study entitled the impact of stock diversity for reducing investments risks. It aimed to identify the different types of stocks, and the role of Khartoum market in conveying information o investors to make the right decision, and to identify the risks that exposed to the financial investment, in order to reach the role of stock diversity in reducing risks. And the researcher has concluded that there is negative relation between diversification and risks.

Examined naive (equal weight) diversification is efficient. He analytically showed that for an infinite population of stocks, a portfolio size of 20 is required to eliminate $95 \%$ of the diversifiable risk on average. However, an addition of 80 stocks (i.e., a size of 100) is required to eliminate an extra $4 \%$ (i.e., $99 \%$ total) of diversifiable risk. This result depends neither on the investment horizons, sampling periods nor the markets involved. But the number of stocks required in portfolio in order to eliminate the same percentage of diversifiable risk differs according to the size of population. For example, in order to eliminate $98 \%$ of diversifiable risk, 50 stocks are required in 10000 stocks population and 22 - in 40 stocks population.

Bekhalid [5] conducted a study where its main objective was to identify the significance of diversification in Financial Securities Portfolio, which leads to reduction of risks with required returns. And the researcher concluded that through sector diversification and accurate control of financial securities with negative correlation between financial securities returns leads to reduction in unsystematic risk and fulfilling high returns.

Zulkifli et al. [6] investigated the optimum number of stock that can help the investor to maximize the benefit of diversification in their investment. Using a simplified approach by Elton et al. [7] a series of portfolio variance was derived to identify the ultimate diversification. 80 samples of stock were randomly chosen from Bursa Malaysia for a period of 1999-2002. The finding was that 13 stocks are enough to make a well diversified portfolio.

Berger et al. [8] conducted study on Russian banks during 1999-2006 and addresses the important question by evaluating the empirical relationship between diversification strategies and the risk return trade-off in banking, and find that banks performance to be non-monotonically related to their diversification strategy, and the marginal effects of focus indices on bank performance are also non linearly associated with level of risk and foreign ownership.

Conducted study to know how financial market efficiency affects a measure of diversification of output across industrial sectors, and find that financial Markets increase substantially the speed with which the observed sectored allocation of output converges towards the optimally diversified benchmark.

Kroch [9] studied the role of international diversification in reducing systematic risks in financial securities portfolio, and concluded that the systemic risks of the portfolio can be reduced by an international diversification and led to relative stability in the return of the portfolio.

Fugazza et al. [10] conducted a study about risk diversification in real estate investments, where the Real estate may thus become more desirable if its returns are negatively serially correlated, and they find that diversification into real estate increases both the Sharpe ratio - a measure of portfolio performance developed by Sharpe- and the certainty equivalent of wealth.

Agate and Seeborg [11] studied the effects of international diversification on portfolio risks, by focusing on stock market indices in the U.S., Shanghai and the European Union, and has concluded that diversification of international stock indices can reduce risk.

They analyzed diversification effects concerning stocks during different market periods of the previous decade, and the study turned out that diversification between sectors is more efficient than diversification between countries. Busse and Ting [12] studied the effects the impact of systemic risk on the diversification benefits of a risk portfolio, and they found out that even with a small probability of occurrence, systemic risk can reduce dramatically the diversification benefits.

Gerard et al. [13] studied the role of industrial structure, currency risk, and country factors on currency returns and their impact on international diversification strategies, and they suggested that country specific factors rather than industrial structure drive international diversification benefits.

$\mathrm{Xu}$ [14] studied the impact of diversification in the Chinese stock market and has shown that holding one or two stocks will subject to huge negative risk adjusted returns. Therefore, Chinese investors can benefit greatly from diversification with a relatively long investment horizon. 
Page 3 of 5

They carried a study on the diversification of portfolios of risky assets. The empirical research was carried out on monthly return data for the S\&P500, with a return history spanning the last five decades. When measuring the diversification of naively allocated 40 -asset portfolios, the average degree of diversification barely exceeds $60 \%$. This result indicates that for the mutual fund manager as well as for the private investor well founded selection of assets indeed leads to better portfolio diversification than naive allocation does [15].

Therefore, based on the literature, the researcher decided to conduct a study of effect of diversification on portfolio risk management at RSSB in order to come up with a reasonable result on how they can be managed.

\section{Methodology}

In this section tools, techniques and methods was used to achieve the research objectives where both primary and secondary data were collected then analyzed through SPSS version 16 so that the correlation and strength between variables can be determined.

\section{Data analysis}

The research is analytical and empirical in nature and makes use of secondary data. The population is the staff from RSSB. The data has been sourced from RSSB financial reports. The sample period undertaken for the objective is from the year 2010 to 2016.

\section{The sample and the sample flame}

Jonghe et al. [15] defined a sampling frame as a list or other device used to define a researcher's population of interest. The sample frame in this study is all those staff at RSSB 124 represented by 84 respondents.

\section{Research instruments}

Primary data and second data collection had been used in order to achieve the research purpose. The primary data had been collected by mean and standard deviation of survey of diversification for portfolio risk management. A questionnaire and a structured interview were developed to a number of 84 respondents at RSSB obtained using Solvins formula used [16]. References have been made to textbooks, journals, newspapers and other published literature, electronic journal and the internet provide as valuable sources of data. Archival method was important for this research. It consisted to gather data from written resources concerning research topic in order to understand the present situation. The literature review bought about comprehensive review involving the collection of both academic theories and research directly related to the study.

\section{Models and techniques}

To determine the relationship between diversification and portfolio risk management, the Pearson correlation coefficient was used. To explain the relationship between diversification and the portfolio risk management the following linear regression model has been also used:

\section{Diversification $=\beta 0+\beta 1$ portfolio risk management $+\varepsilon$}

Where $\beta 0$ is the regression constant, $\varepsilon$ is the error term and $\beta 1$ is the coefficients of independent variable which is the portfolio risk management.

\section{Findings and Results}

The interpretations and analysis were based on the respondents' opinions about the role of diversification on portfolio risk management. Hence, the findings and results are given below.

\section{Characteristics of respondents}

The statistical evidence indicates that at RSSB there is a high proportion of male workers with a frequency of $55(68.8 \%)$ of the total respondents and females with a frequency of $25(38.5 \%)$. This implies that the institution has more male workers than female but does not reflect gender imbalance or discrimination in RSSB. The findings have also shown $50 \%$ of employees at RSSB are ranged between 30 to 40 years old and the last implies the authenticity of the information provided by the respondents and similarly the reliability. However, the results were presented with A0 with 30 (37.5.1\%) of the respondents, Masters with 48 frequency $(60.0 \%)$ and $\mathrm{PhD}$ with $2(2.5 \%)$ of the respondents. This implies that the respondents are educated; knowledge and they have enough skills to achieve the organizational objectives: less than 1 year with a frequency of $21(26.2 \%)$ of the respondents, 2 to 5 years with $32(40.0 \%)$ of the respondents and above 5 years with $27(33.8 \%)$ of the respondents. This indicates many employees working in RSSB have the sufficient experience which can enhance the portfolio risk management.

\section{Analysis of diversification}

In RSSB respondents with mean of 3.0875 and standard deviation of .69708 agree that Diversification is a technique that reduces risk by putting the investment principal in more than one asset, company, market, or country, respondents with a mean of 2.9375 and standard deviation of .66263 , agree that RSSB benefits from diversification because its investment are not perfectly positively correlated, respondents with a mean of 2.9750 and standard deviation of .55060 , agree that Investing in different stocks in the same industry will not reduce the risk better than investing in the stocks from different industries, respondents with a mean of 2.9500 and standard deviation of .59321 , agree that Investing in variety of asset will produce more diversified portfolio than investing in one single asset, and respondents with a mean of 2.3625 and standard deviation of .81511, appreciate the way RSSB diversify its investment portfolio. This implies that RSSB well know the role of diversification in reducing portfolio risks.

\section{Analysis of set allocation}

The role of asset allocation in reducing portfolio risks in RSSB and the results are as follow: the respondents with a mean of 2.6250 and standard deviation of .97273 , agree that Asset allocation is a term used by professional investors to refer to the apportioning of a portfolio among different asset types, respondents with a mean of 2.3250 and standard deviation of .82332 , appreciate the way RRSB allocate its assets to manage risks of its portfolio, respondents with a mean of 2.7750 and standard deviation of .79516, agree that the objective of asset allocation is to optimize the mix of the investments into different asset classes in order to maximize the return of the investment portfolio while minimizing the potential risk, respondents with a mean of 2.1750 and standard deviation of .80779 , agree that Investment department in RSSB assist the board to review assets classes and correlation of returns with applicable benchmarks, and respondents with a mean of 2.8750 and standard deviation of .68205 , agree that RSSB in determining asset allocation it takes into consideration fund's 
risk tolerance. This implies that RSSB well knows the role of asset allocation in reducing risk of its portfolio.

\section{Analysis of economic conditions}

The finding shows the result about economic condition effect on portfolio risk management in RSSB, the respondents with a mean of 2.4000 and standard deviation of .80505 agree that High inflation causes RSSB real investment returns to fall, respondents with a mean of 2.7875 and standard deviation of .83732 agree that RSSB Investment performance is often positively impacted by Economic downturn , respondents with a mean of 2.1500 , and standard deviation of .79715 agree that RSSB invest in treasury bills when there is economy expansion, respondents with a mean of 2.7625 and standard deviation of .95790 , respondents with a mean of 1.9375 and standard deviation of .80101 agree that RSSB invest in fixed income when there is economy contraction this implies that economic condition has a great role in making decision to do diversification in RSSB.

\section{Analysis of portfolio risk management}

The results of the respondents about portfolio risk management in RSSB are as follows: the respondents with a mean of 2.9250 and standard deviation of .65168 agree that risk management occurs any time an investor or fund manager analyzes and attempts to quantify the potential for losses in an investment, respondents with a mean of 2.8375 and standard deviation of .56128 agree that Investing in more securities investors can manage risks of a portfolio, respondents with a mean of 1.8875 and standard deviation of .77938 agree that RSSB manage risks for its portfolio by investing in different regions, respondents with a mean of 3.0875 and standard deviation of .67868 agree that RSSB manage risks of its portfolio by investing in both real estate and fixed income investments, and respondents with a mean of 2.8375 and standard deviation of .68332, this implies that the respondents disagree that RSSB does not manage its portfolio risk by investing in different regions.

\section{Analysis of business risk}

Here findings show the perception of the respondents about business risk in RSSB; respondents with a mean of 2.8500 and standard deviation of .94266 agree that RSSB manage financial risk by investing in more than one asset, respondents with a mean of 2.9750 and standard deviation of .42022 agree that Financial risk is one of unsystematic risks which can be reduced through diversification, respondents with a mean of 2.5625 and standard deviation of .82437 appreciate the way RSSB manage its financial risk, respondents with a mean of 2.5375 and standard deviation of .77857 agree that RSSB investments are nationwide, in most of all the districts in Rwanda most especially in the real estate sector, respondents with a mean of 3.0125 and standard deviation of .66549 agree that Financial Risk stems from the alteration in capital structure of the firm correlated with the company's financing activities. This implies that RSSB uses diversification as key strategy to reduce financial risks.

\section{Relationship between diversification and portfolio risk management}

The linear regression model and the correlation analysis was used to measure the relationship between diversification and portfolio risk management (Table 1).

\begin{tabular}{|l|l|l|l|}
\hline \multirow{3}{*}{ Independent Variable } & & Independent Variable & Dependent Variable \\
\hline & Pearson Correlation & 1 & $.964^{* *}$ \\
\cline { 2 - 4 } & Sig. (2-tailed) & & .000 \\
\cline { 2 - 4 } & $\mathrm{N}$ & 80 & 80 \\
\hline \multirow{3}{*}{ Dependent Variable } & Pearson Correlation & $.964^{* *}$ & 1 \\
\cline { 2 - 4 } & Sig. (2-tailed) & .000 & 80 \\
\cline { 2 - 4 } & $\mathrm{N}$ & 80 & \\
\hline${ }^{* *}$ Correlation is significant at 0.01 levels (2-tailed). & & \\
\hline
\end{tabular}

Table 1: Independent Variables and Dependent Variables.

Based on the data above, the correlation (Pearson) was measured to be $0.964(96 \%)$ which implies that there is a strong positive correlation between diversification and portfolio risk management. There is 0,04 level of errors presented by $4 \%$. After using correlation as test of significance, the null hypothesis ( $\mathrm{H} 0)$ was rejected in favor of alternative hypothesis. Therefore, the researcher concluded that there is significance relationship between the role of diversification and portfolio risk management at $1 \%$ level of significance.

\section{Conclusion and Recommendation}

\section{Conclusion}

The analysis was based on how the organization set the strategies to manage its different activities directed by the workers and to analyze the techniques RSSB used to diversify its portfolio for the purpose to achieve portfolio risk management.

In order to achieve to research's objective, the researcher have been used the questionnaires which have been answered by the workers at RSSB. This research studied the different categories includes both gender respondent: male were $68.8 \%$ and female $32.5 \%$; different age: $31.2 \%$ were 20 -30years; $50 \%$ were 30 -40years and $18.8 \%$ were above 40 
years, different education level: $37.51 \%$ of the respondent have A0, $60 \%$ of the respondents have MBA, $2.5 \%$ of the respondent have PHD. The perception of the respondents on diversification presented by an overall mean of 2.8625 ( $\mathrm{SD}=0.663726$ ), the perception of respondents on asset allocation are presented by an overall mean of 2.555 ( $\mathrm{SD}=0.81621$, the perception of the respondents economic conditions are presented by an overall mean of 2.4075 ( $\mathrm{SD}=0.83968)$, the perception of the respondents on portfolio risk management are presented by an overall mean of $2.715(\mathrm{SD}=0.67086)$, the perception of the respondents on business risk are presented by an overall mean of 2.9175 ( $\mathrm{SD}=0.62059)$, and the perception of the respondents on financial risk are presented by an overall mean of $2.7875(\mathrm{SD}=0.72626)$.

Pearson correlation coefficient between diversification indicators and portfolio risk management, statistical evidence depicts that there is a significance relationship between diversification and portfolio risk management $(0.964)$. The coefficient indicates the correlation is positively a strong correlation and the p-value is 0.000 , which is less than 0.01. After using correlation as test of significance, the null hypothesis $\mathrm{H} 0$ : was rejected in favor of alternative claim at $1 \%$.

\section{Recommendations}

After conducting this research, the researcher recommends the following:

1. RSSB should improve international diversification to reduce its portfolio risk,

2. RSSB should also reduce risks through the purchase of a mutual fund and should not directly invest in securities with maturities greater than the limits imposed by investment policy,

3. RSSB should be aware of their risk tolerance and confirm that the market risk they assume is within this tolerance level.

For further studies should focus in the areas of diversification on portfolio risk management, especially the role of asset allocation on business risk reduction, the impact of economic conditions on unsystematic risk management.

\section{References}

1. Harvey CR, Gray S (2002) Portfolio Analysis and Diversification.

2. Ross (2008) Risk and Return, market history. Fundamentals of Corporate Finance, (9th ed.), McGraw-Hill Companies, Inc. New York.

3. Markowitz HM (1991) Portfolio Selection: Efficient Diversification of Investments. New York.

4. Reilly FK, Brown KC (2009) Investment Analysis: Portfolio Management. Thomson South-Western.

5. Bekhalid (2007) The diversification as a tool to reduce unsystematic risks in financial securities portfolio, unpublished MA thesis, Warkala University.

6. Zulkifli M, Basarudin SB, Norzaidi MD, Siong SC (2010) A study on diversification in Malaysian stock market. EABR \& TLC Conference Proceedings. Rothenberg, Germany.

7. Elton EJ, Gruber MJ, Padberg MW (1977) Simple criteria for optimal portfolio selection. Journal of Finance, pp: 1341-1348.

8. Berger AK, Hasan I, Korhonen I, Zhou M (2010) Does diversification increase or decrease bank risk and performance? Evidence on diversification and the risk return trade-off in banking, Bofit paper.

9. Kroch (2010) the international diversification as a tool of reducing the systematic risk in financial securities portfolio, unpublished Ma thesis, Kadi Merbah University.

10. Fugazza C, Nicodano G, Guidolin M (2009) Investing for the Long-Run in European Real Estate. Journal of Real Estate Finance and Economics 34: 5-80.

11. Agate A, Seeborg M (2007) The effect of international diversification on portfolio risk, Illiones Wesleyan University.

12. Busse JA, Tong Q (2013) Mutual fund industry selection and persistence. Review of Asset Pricing Studies 2: 245-274.

13. Gerard LF, Varma K, Corliss SB, Linn C (2002) Professional development for technology-enhanced Inquiry science. Review of Educational Research 81: 408-448.

14. Xu Y (2003) Diversification in the Chinese stock market.

15. Jonghe OD, Baele L, Vennet RV (2009) Does the stock market value bank diversification? Journal of Banking and Finance 31: 1999-2023.

16. Kothari CR (2004) Research methodology: Method and techniques, New Age International (P) Limited. 